\title{
Domestic Violence Against Married Women During the COVID-19 Quarantine in Saudi Arabia
}

Fares F Alharbi 1, 2, 3 , Meshal A. Alkheraiji 4, 5, 3, 2 , Abdullah A. Aljumah 1, 2, 3 , Majid Al-Eissa 6, 2, 3 , Salman S. Qasim 3, 2 , Meshal K. Alaqeel 1, 2, 3

1. Mental Health, Ministry of the National Guard Health Affairs, Riyadh, SAU 2. Research Office, King Abdullah International Medical Research Center, Riyadh, SAU 3. College of Medicine, King Saud Bin Abdulaziz University for Health Sciences, Riyadh, SAU 4. Psychiatry, King Saud University, Riyadh, SAU 5. Psychiatry, King Saud University Medical City, Riyadh, SAU 6. Pediatrics, Ministry of the National Guard Health Affairs, Riyadh, SAU

Corresponding author: Fares F Alharbi, faris137@hotmail.com

\section{Abstract}

\section{Background}

Before the coronavirus disease 2019 (COVID-19) pandemic, cases of domestic abuse and aggressive behaviour between Saudi married couples were increasing annually, a topic of growing concern both socially and medically. With the forced indoor confinement enacted as a containment measure, international studies regarding domestic abuse indicated an almost unanimous increase in prevalence. This cross-sectional national study aimed to assess the change between the pre-and intra-pandemic prevalence of abuse in Saudi Arabia.

\section{Material and methods}

Anonymous data were gathered using a web-based Arabic version of the World Health Organization (WHO) multi-country instrument measuring violence against women residing in Saudi Arabia. The previously validated questionnaire included a series of multiple-choice questions related to demographic information, family infrastructure, experienced situations of abuse, and the severity and form of abuse during the quarantine period, from March 23, 2020, to June 21, 2020. Associations were tested using a two-tailed Pearson's Chi-square test and odds ratios. A binary multivariate logistic regression was used to identify the independent factors associated with domestic violence.

\section{Results}

In total, 2254 participants were included in the present study. The majority ( $\mathrm{n}=2129,94.7 \%)$ were Saudi nationals. The highest proportion ( $\mathrm{n}=1022,45.3 \%$ ) was in the 30 to 40 years age group. The self-reported prevalence of domestic violence before COVID-19 pandemic and quarantine was $25.4 \%$ and $16.6 \%$ during the confinement, indicating an overall decrease of $8.8 \%$ in the reported cases. Regarding the type of violence, of the 315 (16.6\%) women who endured violence since the confinement, the majority $(\mathrm{n}=301$, 95.6\%) experienced multiple forms of violent abuse, 264 (87.7\%) suffered from psychological/emotional violence, 114 (37.9\%) from physical violence, and 50 (16.6\%) from sexual violence. Of the group who experienced multiple forms of violence, 120 (39.9\%) reported an increase in the frequency and perceived intensity of the violence since the confinement. The only variable that directly increased the likelihood of suffering domestic violence had more than three children $[\mathrm{OR}=1.59, \mathrm{P}=0.018]$.

\section{Conclusions}

Contrary to trends observed in other countries, the national prevalence of abusive conduct towards married women showed a marked decrease during the quarantine period-more children directly correlated with a higher reported frequency of being abused. Further studies in neighbouring countries with comparable societies and structures must be conducted to assess the validity of our findings in the context of the global trends of violence in the marital home.

Categories: Family/General Practice, Public Health, Epidemiology/Public Health

Keywords: covid-19, domestic violence, married women, abuse, saudi arabia

\section{Introduction}

During the coronavirus disease 2019 (COVID-19) pandemic, healthcare services could not meet the exponential increase in demands on resources, leading to the entire population's subsequent forced confinement in almost every affected country, including Saudi Arabia [1-5]. In addition to the forced indoor confinement, other measures implemented and still actively enforced include the compulsory wearing of surgical masks or visors in enclosed public spaces, mandatory self-isolation with suspected infection, and physical distancing and isolation [6-8]. The social and community health consequences of these measures are now becoming more apparent and concerning as the rate of depression, suicide, substance abuse, and 
domestic violence are steadily increasing [9-11]. As a general definition, domestic violence is any purposeful attack by one or more close relatives or acquaintances through psychological, physical, or sexual acts of aggression or violence with an intent to compel, control, or debase the victim $[10,12,13]$.

In a world where a person is legally bound to remain indoors, domestic violence may potentially have the most lasting and far-reaching harm. Unlike most other consequences of forced confinement, domestic violence endangers the individual and adversely affects all those around to varying degrees. The consequences often present in later life as post-traumatic stress disorder or academic failure [12-14]. Literature related to this subject offers substantial support for these practices' serious nature, providing evidence that between a quarter and two-thirds of the perpetrators are intimate partner. Approximately one-third of the cases require urgent medical assistance. Literature also reports problems related to academic performance in not attending classes or altogether dropping out from the school of children who suffered domestic violence [15-17].

In Saudi Arabia, studies before the pandemic and enforced quarantine reported that the lifetime prevalence of domestic violence ranged between $33 \%$ and $45 \%$ for married women $[13,18,19]$, high in the context of a comparatively calm period. The first step to controlling such a problem is to assess its current state. The current study aimed to evaluate the existing prevalence of domestic violence in Saudi families and establish a predicted change rate using past and present values as reference. In addition, the study aimed to determine whether factors related to the demographic information, financial status or matrimony could identify individuals who are at a higher risk of domestic abuse.

\section{Materials And Methods}

This was a cross-sectional study using a convenience sampling technique. The inclusion criteria were married women, at least 18 years of age, living in Saudi Arabia during the quarantine period, from March 23, 2020 , to June 21, 2020. Eligible participants were approached through social media, including but not limited to Twitter and WhatsApp. The data were collected using an Arabic version of the World Health Organization (WHO) multi-country instrument related to violence against women [18,20]. The self-assessment questionnaire included sections about the demographic characteristics of the married women, such as age, level of education, income, and occupation. The questionnaire also covered the type of consanguinity between married women and their spouses. The duration of the marriage, state of living with another wife in the same house, and the presence of children from another wife were also assessed. In addition, the questionnaire included questions about the risks and protective factors of intimate partner violence in the four domains of domestic abuse against women: physical, psychological, sexual, and economic abuse. In each domain, data were collected as present and past exposure to violence and frequency of violence (always, sometimes, rarely, or never). Screening for violence was considered positive when responding to a question about intimate partner violence was (always). The prevalence of the different forms of domestic violence was estimated based on the number of responses. The prevalence of violence in Saudi Arabia was estimated based on the positive responses to any form of violence towards the married female. The sections related to general health were not included in the current study for the sake of simplicity and time constraints.

The sample included both Saudi and non-Saudi married women. According to the Saudi General Authority for Statistics, 4,832,830 Saudi and non-Saudi females are married between the age of 15 and 64 years [21]. According to the Raosoft Digital Sample Size Calculator (Raosoft, Inc., Seattle, WA; http:/www.raosoft.com/samplesize.html), the minimum recommended sample size get a representative randomized sample with a $99 \%$ level of confidence, and a 5\% margin of error was approximately 700 married women. The data were compiled in Microsoft Excel 2010 (Microsoft, Redmond, WA, USA) and analyzed through the Statistical Package for Social Sciences (SPSS) Statistics version 23 (IBM Corp., Armonk, NY, USA). Categorical variables are represented as frequency and percentage, and associations were tested using a two-tailed Pearson's Chi-square test and odds ratios. A binary multivariate logistic regression analysis was used to identify the independent factors associated with domestic violence. A p-value of $\leqslant 0.01$ for the associations between the variables and a $\mathrm{p}$-value of $\leqslant 0.05$ for the odds ratio precision testing was deemed significant.

The Institutional Review Board approved the present study of King Abdullah International Medical Research Center, Ministry of National Guard-Health Affairs, Riyadh, Saudi Arabia (approval number RC20/218/R, April 28,2020 ). Patient data were obtained and used by only the study team, ensuring patient confidentiality and privacy.

\section{Results}

In total, 2254 participants were included in the present study. The majority ( $\mathrm{n}=2129,94.7 \%)$ were Saudi nationals. The highest proportion ( $\mathrm{n}=1022,45.3 \%)$ was in the 30 to 40 years age group, $1408(65.7 \%)$ had a college-level education, and a half ( $\mathrm{n}=1079,50.2 \%)$ were employed. Of the employed group, 688 (72.3\%) were government employees. A summary of the demographic characteristics of the participants is shown in Table 1 . 


\section{Cureus}

Characteristic

n (\%)

Nationality $(n=2247)$

Saudi

$2129(94.7)$

Non-Saudi

118 (5.3)

Age group, years $(n=2254)$

30 and below

$31-40$

41-50

Above 50

702 (31.1)

1022 (45.3)

387 (17.2)

$143(6.3)$

Number of children $(n=2254)$

None

244 (10.8)

1-2

724 (32.1)

$3-5$

794 (35.2)

More than 5

492 (21.8)

Level of education $(n=2144)$

Able to read and write

$13(0.6)$

Below high school

64 (3.0)

High school

294 (13.7)

College

1408 (65.7)

Post-graduate studies

365 (17.0)

Employment $(n=2151)$

Employed

$1079(50.2)$

Unemployed

1072 (49.8)

Type of employment ( $n=951)$

Government employee

$688(72.3)$

Private sector employee

$200(21.0)$

Others

$63(6.6)$

\section{TABLE 1: Demographic characteristics of married women}

The self-reported prevalence of domestic violence before the COVID-19 pandemic and quarantine was $25.4 \%$ and $16.6 \%$ during confinement, indicating an overall decrease of $8.8 \%$ in the reported cases. Regarding the type of violence, of the 315 (16.6\%) women who endured violence since the confinement, the majority ( $\mathrm{n}=301,95.6 \%)$ experienced multiple forms of violent abuse, 264 (87.7\%) suffered from psychological/emotional violence, 114 (37.9\%) from physical violence, and 50 (16.6\%) from sexual violence. Of the group who experienced multiple forms of violence, 120 (39.9\%) reported an increase in the frequency and perceived intensity of the violence since the confinement, 128 (42.5\%) reported an unchanged frequency and intensity of violence. The remaining 53 (17.6\%) noted a reduction in violent outbursts (Table 2). 


\section{Cureus}

Outcome variables

n (\%)

Prevalence of domestic violence $(n=1901)^{\star}$

Before COVID-19

$483(25.4)$

Since COVID-19

315 (16.6)

Did not encounter domestic violence

$1103(58)$

Type of domestic violence (multiple responses) $(n=301)$

Physical

$114(37.9)$

Psychological/emotional

264 (87.7)

Sexual

50 (16.6)

Frequency and intensity of domestic violence since the COVID-19 pandemic $(n=301)$

Increased

$120(39.9)$

Unchanged

128 (42.5)

Decreased

40 (13.3)

Stopped

$13(4.3)$

TABLE 2: Prevalence, type, and intensity of domestic violence among married women

COVID-19: coronavirus disease 2019

*No response for outcome variable $(n=353)$

Of all of the variables, only the number of offspring had a statistically measurable effect on the probability of being subjected to violence by the husband or close family members. The results indicated that with more than three children, the probability of abuse increased proportionally with each successive child [OR $=1.59$, $\mathrm{P}=0.018]$ (Table 3).

\begin{tabular}{|c|c|c|c|c|}
\hline \multirow{2}{*}{ Characteristic } & \multicolumn{2}{|c|}{ Domestic violence } & \multirow{2}{*}{ P-value } & \multirow{2}{*}{ OR (Cl 95\%) } \\
\hline & Yes & No & & \\
\hline \multicolumn{5}{|c|}{ Nationality (n=482; 1415) } \\
\hline Saudi & $452(25.1)$ & $1352(74.9)$ & \multirow{2}{*}{0.120} & 1.0 (reference) \\
\hline Non-Saudi & 30 (32.3) & $63(67.7)$ & & $1.42(0.91-2.30)$ \\
\hline \multicolumn{5}{|c|}{ Age group, years $(n=483 ; 1418)$} \\
\hline 30 and below & $129(22.2)$ & $453(77.8)$ & \multirow{4}{*}{0.188} & 1.0 (reference) \\
\hline $31-40$ & $232(26.9)$ & $629(73.1)$ & & $1.29(1.01-1.66)$ \\
\hline $41-50$ & $93(27.0)$ & $251(73.0)$ & & $1.19(0.75-1.91)$ \\
\hline Above 50 & $29(25.4)$ & 85 (74.6) & & \\
\hline \multicolumn{5}{|c|}{ Vital status of the father $(n=481 ; 1416)$} \\
\hline Alive & $416(24.7)$ & 1267 (75.3) & \multirow{2}{*}{0.258} & 1.0 (reference) \\
\hline Deceased & $65(30.5)$ & $148(69.5)$ & & $1.14(0.91-1.42)$ \\
\hline \multicolumn{5}{|c|}{ Vital status of the mother $(n=481 ; 1415)$} \\
\hline Alive & $416(24.7)$ & $1267(75.3)$ & \multirow{2}{*}{0.067} & 1.0 (reference) \\
\hline Deceased & $65(30.5)$ & $148(69.5)$ & & $1.34(0.98-1.83)$ \\
\hline
\end{tabular}




\section{Cureus}

Number of male siblings $(n=483 ; 1418)$

None

$1-5$

More than 5

Number of female siblings $(n=483 ; 1418)$

None

$1-5$

More than 5

Number of children $(n=483 ; 1418)$

None

$1-2$

3-5

More than 5

Level of education $(n=483 ; 1415)$

Able to read and write

Below high school

High school

College

Post-graduate studies

Employment $(n=483 ; 1418)$

Employed

Unemployed

Type of employment $(n=213 ; 650)$

Government employee

Private sector employee

Others
$20(25.0)$

$410(26.0)$

$53(21.7)$

26 (32.9)

367 (24.8)

90 (26.2)

45 (19.3)

$166(23.7)$

212 (27.6)

$60(30.3)$

$2(25.0)$

$6(75.0)$

19 (33.9)

67 (26.5)

186 (73.5)

926 (74.1)

260 (78.5)

71 (21.5)

226 (24.0)

717 (76.0)

257 (26.8)

701 (73.2)

461 (74.1)

143 (77.3)

46 (82.1)
1.0 (reference)

1.05 (0.63-1.77)

$0.83(0.46-1.50)$

1.0 (reference)

$0.67(0.41-1.09)$

$0.72(0.43-1.22)$

1.0 (reference)

$1.29(0.89-1.87$

0.018

1.59 (1.11-2.28)

$1.82(1.16-2.83)$

$1.22(0.24-6.18)$

$1.88(1.02-3.47)$

$1.32(0.90-1.93)$

$1.28(0.96-1.71)$

1.0 (reference)

1.0 (reference)

$1.16(0.95-1.43)$

$1.61(0.79-3.26)$

1.35 (0.63-2.90)

1.0 (reference)

TABLE 3: Association between prevalence of domestic violence and sociodemographic characteristics of married women

Cl: confidence interval; OR: odds ratio

\section{Discussion}

Before the COVID-19 pandemic, studies in Saudi Arabia indicated a high prevalence of domestic violence and abuse $[13,18,19,22,23]$. After the pandemic containment measures were implemented, studies reported that the rates were increasing in most countries and communities, mandating additional measures to control and report domestic violence [10,14]. The same trend was expected when we planned this intra-pandemic study in the Saudi population. However, we found that the national prevalence of domestic violence decreased by $8.8 \%$ during the quarantine period. This result, while encouraging, still requires an explanation as little corroboration is available in almost all literature related to the subject during the pandemic.

It should be noted that the current study measured domestic violence during the COVID-19 pandemic and not the lifetime risk of domestic violence. For example, if a woman was not subjected to domestic violence during the quarantine, this does not necessarily mean that she did not encounter domestic violence before the quarantine. The findings should not be incorrectly applied to a lifetime prevalence of domestic violence. In other communities, domestic violence during the COVID-19 pandemic showed different prevalence rates. 
Studies conducted in the United States of America reported a 10 to 27\% increase in domestic violence during the COVID-19 pandemic [24,25]. In the WHO Europe member states, there was a $60 \%$ rise in emergency calls from women subjected to violence by their intimate partner [26]. This disparity could be explained if it is taken into account that culturally distinct groups have varying definitions and valuations of domestic violence boundaries. Another possible explanation is that the forced isolation between family members may have had a positive impact on intra-family relations by reducing the number of people per house at any given time. In Saudi society, it is prevalent for the extended family of the wife or husband to congregate in one abode, living in very close proximity with each other, affording little privacy, space, or peace of mind for the large part of the day and night. During the quarantine, however, extended family members were required to stay at home with their immediate family only, resulting in less overcrowding, more attention and intimacy between the husband and wife, and fewer outbursts of dissatisfaction by either party. The uncertainty that shrouds all societies' future due to the quarantine and pandemic may have forced families and couples to become more lenient and understanding, which is essential for cohabitation when no other options are available. Practicality and necessity are strong motivators for dialogue.

There were several limitations to the present study. Only those who are literate and had access to the internet, whether through smartphones or laptops, could complete the questionnaire. Considering the quarantine period, however, this was the most effective way of reaching out to people to recognize domestic violence among married women. Moreover, the spread of participants across Saudi Arabia may have been limited to individuals with an interest in and experience of domestic abuse, limiting the generalizability of our findings. Although the incidence of violence during the quarantine was lower than in other studies, the victims' perceptions of the intensity of violence were noticeably higher than before the quarantine. The necessary tools and methods to quantify this perceived increase of the intensity of violence were not part of this research design and authorized scope. As records of past events related to domestic violence are not available, we cannot offer any view. In addition to the fear or uncertainty of being discovered by the abusive spouse, there is also a robust socially imposed taboo on speaking openly of what goes on between couples or close family behind closed doors, and that for this reason, the number of reports may not be a true representation of actuality $[10,14,24]$.

\section{Conclusions}

During the quarantine period, the prevalence rate of domestic violence in Saudi Arabia showed a marked decrease compared to the rates reported before the COVID-19 pandemic. The current study outcomes are inconsistent with the literature, allowing a cautiously optimistic outlook for the future of our society and women's rights. We endorse more measures and strategies to provide assistance and support for female victims of domestic violence. Awareness campaigns should be implemented in Family Medicine and premarital examination clinics, highlighting the impact of domestic violence on interpersonal relationships. Additional studies in neighbouring countries with comparable societies and structures must be conducted to assess the validity of our findings in the context of the global trends in violence in the marital home.

\section{Appendices}




\section{Cureus}

Domestic Violence Questionnaire

Nationality

Age

Is your father alive?

Is your mother alive?

How many male siblings do you have?

How many female siblings do you have?

How many children do you have?

What is the highest level of education that you achieved?

Do you have a job or private source of income?

If yes, what is the nature of the job?

Before the COVID-19 pandemic, were you ever exposed to marital violence?

Since the COVID-19 pandemic, were you ever exposed to marital violence?

Since the COVID-19 pandemic, has the frequency of violence (times of its occurrence) and intensity changed?

What is the nature of the abuse? (you can choose more than one answer) $\square$ Saudi $\square$ Non-Saudi

\author{
$\square$ Yes $\square$ No \\ $\square$ Yes $\square$ No \\ $\square$ None $\square$ 1-5 $\square$ More than 5 \\ $\square$ None $\square$ 1-5 $\square$ More than 5 \\ $\square$ None $\square$ 1-2 $\square$ 3-5 $\square$ More than 5 \\ $\square$ Able to read and write $\square$ Below high school $\square$ High school \\ $\square$ College $\square$ Post-graduate studies \\ $\square$ Yes $\square$ No \\ $\square$ Government employee $\square$ Private sector employee $\square$ Others
}

$\square$ Yes $\square$ No

$\square$ Yes $\square$ No

$\square$ Increased $\square$ Continued the same $\square$ Decreased $\square$ Stopped

$\square$ Physical $\square$ Psychological/Emotional $\square$ Sexual

TABLE 4: Domestic Violence Questionnaire

\section{Additional Information \\ Disclosures}

Human subjects: Consent was obtained or waived by all participants in this study. King Abdullah International Medical Research Center issued approval RC20/218/R. The present study was approved by the Institutional Review Board of King Abdullah International Medical Research Center, Ministry of National Guard-Health Affairs, Riyadh, Saudi Arabia (approval number RC20/218/R). Patient data were obtained and used by only the study team, ensuring patient confidentiality and privacy. . Animal subjects: All authors have confirmed that this study did not involve animal subjects or tissue. Conflicts of interest: In compliance with the ICMJE uniform disclosure form, all authors declare the following: Payment/services info: All authors have declared that no financial support was received from any organization for the submitted work. Financial relationships: All authors have declared that they have no financial relationships at present or within the previous three years with any organizations that might have an interest in the submitted work. Other relationships: All authors have declared that there are no other relationships or activities that could appear to have influenced the submitted work.

\section{Acknowledgements}

We would like to thank PubHelper LLC for their help and support in writing, language, proofreading our article, and advice offered. We would also like to thank King Saud bin Abdulaziz University for Health Sciences (KSAU-HS) for their encouragement and support in conducting this research. We would also like to thank Dr Shaik Shaffi Ahamed for his help in the data analysis and writing the results section. Finally, we would like to thank all the anonymous participants who submitted their data to us at risk for themselves to better understand and aid them in their need for social and legal support.

\section{References}

1. Kaba AJ, Kaba AN: COVID-19 in African countries versus other world regions: a review . Afr J Reprod Health. 2020, 24:125-41. 10.29063/ajrh2020/v24i2s.17

2. Khachfe HH, Chahrour M, Sammouri J, Salhab H, Makki BE, Fares M: An epidemiological study on COVID19: a rapidly spreading disease. Cureus. 2020, 12:e7313. 10.7759/cureus.7313

3. Park SE: Epidemiology, virology, and clinical features of severe acute respiratory syndrome -coronavirus-2 (SARS-CoV-2; Coronavirus Disease-19). Clin Exp Pediatr. 2020, 63:119-24. 10.3345/cep.2020.00493

4. Parodi IC, Poeta MG, Assini A, Schirinzi E, Sette PD: Impact of quarantine due to COVID infection on 
migraine: a survey in Genova, Italy. Neurol Sci. 2020, 41:2025-7. 10.1007/s10072-020-04543-X

5. Saudi Arabia imposes 24-hour curfew in Riyadh and other cities . (2020). Accessed: March 28, 2021: https://www.reuters.com/article/us-health-coronavirus-saudi-curfew/saudi-arabia-imposes-24-hourcurfew-in-riyadh-and-....

6. Buitrago-Garcia D, Egli-Gany D, Counotte MJ, et al.: Occurrence and transmission potential of asymptomatic and presymptomatic SARS-CoV-2 infections: A living systematic review and meta-analysis. PLoS Med. 2020, 17 :e1003346. 10.1371/journal.pmed.1003346

7. Hanson KE, Caliendo AM, Arias CA, et al.: Infectious Diseases Society of America guidelines on the diagnosis of coronavirus disease 2019 (COVID- 19): serologic testing. Clin Infect Dis. 2020, 10.1093/cid/ciaa1343

8. Luo L, Liu D, Liao XL, et al.: Modes of contact and risk of transmission in COVID-19 among close contacts [Pre-print]. MedRxiv. 2020, 10.1101/2020.03.24.20042606

9. Bradbury-Jones C, Isham L: The pandemic paradox: the consequences of COVID-19 on domestic violence . J Clin Nurs. 2020, 29:2047-9. 10.1111/jocn.15296

10. Staying safe during COVID-19. (2020). Accessed: March 28, 2021: https://www.thehotline.org/resources/staying-safe-during-covid-19/.

11. Serafini G, Parmigiani B, Amerio A, Aguglia A, Sher L, Amore M: The psychological impact of COVID-19 on the mental health in the general population. QJM. 2020, 10.1093/qjmed/hcaa201

12. Flury M, Nyberg E, Riecher-Rössler A: Domestic violence against women: definitions, epidemiology, risk factors and consequences. Swiss Med Wkly. 2010, 140:23-7. 10.4414/smw.2010.13099

13. Wali R, Khalil A, Alattas R, Foudah R, Meftah I, Sarhan S: Prevalence and risk factors of domestic violence in women attending the National Guard Primary Health Care Centers in the Western Region, Saudi Arabia, 2018. BMC Public Health. 2020, 20:239. 10.1186/s12889-020-8156-4

14. A snapshot of domestic violence during COVID-19. (2020). Accessed: March 28, 2021: https://www.thehotline.org/resources/a-snapshot-of-domestic-violence-during-covid-19/.

15. Jewkes R, Fulu E, Naved RT, Chirwa E, Dunkle K, Haardörfer R, Garcia-Moreno C: Women's and men's reports of past-year prevalence of intimate partner violence and rape and women's risk factors for intimate partner violence: a multicountry cross-sectional study in Asia and the Pacific. PLoS Med. 2017, 14:e1002381. 10.1371/journal.pmed.1002381

16. The economic cost of intimate partner violence, sexual assault, and stalking . (2017). Accessed: March 28, 2021: https://iwpr.org/iwpr-general/the-economic-cost-of-intimate-partner-violence-sexual-assault-andstalking/.

17. Walsh TB, Seabrook RC, Tolman RM, Lee SJ, Singh V: Prevalence of intimate partner violence and beliefs about partner violence screening among young men . Ann Fam Med. 2020, 18:303-8. 10.1370/afm.2536

18. Abolfotouh MA, Almuneef M: Prevalence, pattern and factors of intimate partner violence against Saudi women. J Public Health (Oxf). 2020, 42:e206-14. 10.1093/pubmed/fdz092

19. Afifi ZE, Al-Muhaideb NS, Hadish NF, Ismail FI, Al-Qeamy FM: Domestic violence and its impact on married women's health in Eastern Saudi Arabia. Saudi Med J. 2011, 32:612-20.

20. Garcia-Moreno C, Jansen HA, Ellsberg M, Heise L, Watts CH: Prevalence of intimate partner violence: findings from the WHO multi-country study on women's health and domestic violence. Lancet. 2006, 368:1260-9. 10.1016/S0140-6736(06)69523-8

21. Annual yearbook | General Authority for Statistics . (2021). Accessed: April 2, 2021: https://www.stats.gov.sa/en/46.

22. Hawcroft C, Hughes R, Shaheen A, et al.: Prevalence and health outcomes of domestic violence amongst clinical populations in Arab countries: a systematic review and meta-analysis. BMC Public Health. 2019, 19:315. 10.1186/s12889-019-6619-2

23. Kazzaz YM, AlAmeer KM, AlAhmari RA, Househ M, El-Metwally A: The epidemiology of domestic violence in Saudi Arabia: a systematic review. Int J Public Health. 2019, 64:1223-32. 10.1007/s00038-019-01303-3

24. Boserup B, McKenney M, Elkbuli A: Alarming trends in US domestic violence during the COVID-19 pandemic. Am J Emerg Med. 2020, 38:2753-5. 10.1016/j.ajem.2020.04.077

25. Sharifi F, Larki M, Roudsari RL: COVID-19 outbreak as threat of violence against women . J Midwifery Reprod Health. 2020, 8:2376-9. 10.22038/jmrh.2020.16036

26. Mahase E: COVID- 19: EU states report 60\% rise in emergency calls about domestic violence . BMJ. 2020, 369:1872. 10.1136/bmj.m1872 